\title{
Shadow education: Effects on students' self-efficacy in science
}

Montebon, Darryl Roy T.

Institute of Teaching and Learning, Philippine Normal University, Philippines (montebon.drt@ pnu.edu.ph)

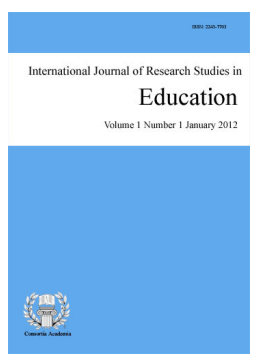

ISSN: $2243-7703$ Online ISSN: 2243-7711

OPEN ACCESS

\section{Abstract}

This study aims to investigate the effect of shadow education on students' self-efficacy. Shadow education or tutoring mimics the mainstream form of education (Bray, 1999) while self-efficacy is a personal judgment of one's capability to plan and execute a course of action to achieve a certain goal (Bandura, 1977 as cited by Zimmerman, 2000). Results of this study described the tutorial background of the respondents and their self-efficacy levels. It has been found out that students' self-efficacy due to exposure to shadow education is high. The self-efficacy of students does not necessarily vary when compared by gender, grade level, and the length of time that respondents have been going to tutorial sessions.

Keywords: shadow education; tutoring in science; self-efficacy in science; shadow education in the Philippines 


\section{Shadow education: Effects on students' self-efficacy in science}

\section{Introduction}

Tutoring after class has been a practice in Chinese-Filipino schools in the Philippines. Students oftentimes go to tutor houses or they pay private tutors at home after official school hours. Subjects like Science, Math, and Chinese Language are the often subjects that students need help with. Tutoring is considered to be a form of shadow education since it mimics the form of mainstream education and could not be considered as a formal training (Bray, 1999).

The reason for seeking tutors is mostly academic. Ireson and Rusforth (2005) reported that parents seek tutor support for reasons such as understanding of the subject, increase self-confidence, and achieve high examination scores. Based on the experience of the researcher who is a shadow teacher himself, tutoring after class is a must for Chinese-Filipino students to achieve and succeed in school. Though parents pay expensive tuition fees in private schools for their child's education, they are still willing to pay extra money to support them with their academic needs. But how does tutoring affect students aside from their academics? Does it have an impact on their belief to succeed? To answer these questions, this research was undertaken.

It is the goal of this research to investigate the impact of shadow education on students' self-efficacy or their belief in their personal abilities to accomplish tasks and overcome challenges. While the aim of shadow education is to assist students in their academic life, it is also important to investigate how it affects students' belief to make it on their own at school where the tutor is not around to help.

This research is to primarily help shadow teachers or tutors assess areas for improvement in the tutorial system to find ways to help students not just with their academics but on their personal development as well. The impact of shadow education to students' self-efficacy is an important area to be studied since tutoring is a form of system support and once it is taken may have a serious effect on students. Moreover, this research aims to add knowledge in the field of shadow education. Bray (1999) described that the field of shadow education is not yet well studied since it's a close system that most researchers do not have a direct access with. Shadow education centers are hard to penetrate due to privacy reasons.

\section{Review of Related Literature}

Shadow education can be referred to as the set of activities that are similar to formal school activities to assist students with their needs to increase their chance of success in school (Stevenson \& Baker, 1992 as cited by Choi, 2014). These activities particularly include tutoring. Bray (1999) reported that tutoring has been a common practice among Asian countries like Cambodia, Malaysia, and Taiwan. In the Philippines, the number of tutorial centers had increased significantly since 1994 (Guzman \& de Castro, 2013).

Heyneman (2011) reported that shadow education has been employed because the parents have a natural tendency to support their child with their education in any way possible. Further, he listed reasons for tutoring to be mainly for enrichment, remediation, and preparation for examinations. Tutoring should also be encouraged since good education is a good investment in human capital and such investment can benefit the society in general.

How and when does tutoring happen? Bray (1999) described the process to be like that of a producer and consumer relationship. The producers of the tutoring system can be provided by the mainstream teachers or experts that provide tutorial services. The consumers may be the students referred to by their teachers to tutor or those that personally seek assistance. 
$>$ Experience individualized, systematic, structured learning experience

$>$ Observe congruence between teacher and learner, closer role model

$>$ Improvement in academic performance and personal growth

$>$ Improvement in attitude toward subject area

$>$ Stronger effects than other individualized teaching strategies

$>$ Motivation to self-paced and self-directed learning.

$>$ Intensive practice on different academic for students who need it

$>$ Improvement of self esteem.

Why is studying shadow education important? Bray (1999) described that shadow education works like that of a sun dial. It tells what the society should respond to in its educational system. Though the primary focus of research is the mainstream education, shadow education should not be taken as a passive entity because it affects the mainstream education in a positive or a negative way.

Some benefits of shadow education include the reduction of the workload of the main stream teachers particularly in instruction. Students get to better understand concepts taught in the classroom with the help of tutors. Follow up and practice exercises are being provided so that when the student gets into the classroom, he or she is ready for the academic tasks for the day. However in certain countries, private tutoring poses a threat to government systems and can be problematic (Bray, 2009). The mainstream teachers may utilize the situation to force tutoring classes to their students and cite reasons such as not covering the topic, or worst, they purposely slow down the pacing of the lesson to make sure that tutoring classes will be done. In doing so, mainstream teachers get extra income. Such practice can be considered as a form of corruption. Thus, shadow education system should be monitored and regulated.

Mark Bray (1999) suggests that the impact of shadow education on students' academic achievement should be further studied. The researches that he cited showed inconsistent results because of several factors. He cited that the data collected in shadow education researches are not comparable with each other since the homogeneity of the respondents is variable. Moreover, he reiterated that shadow education is a rich area for research since only few studies have been conducted about it. This is because it is harder to obtain data from shadow education institutions compared with the mainstream schools.

With this idea in mind, it is the hope of this research to contribute to the existing knowledge in shadow education researches by studying one factor that affects students' academic achievement, self-efficacy. Britner and Pajares( 2006) stated that self-efficacy is a strong predictor of academic achievement across disciplines and even grade level. They elaborated further that students that are studying science who have high self-efficacy are the ones that often achieve in the class as well as choose science as a career.

"I think therefore I can" is the concept of self-efficacy. It is a belief to finish a task successfully because of one's ability. It is a personal judgment of one's capability to plan and execute a course of action to achieve a certain goal (Bandura, 1977 as cited by Zimmerman, 2000). Self-efficacy is a measure of the ability rather than the quality. Such capability determines chances of success rate. This efficacy belief differs however in different situations, thus self-efficacy is context dependent. A student with a high self-efficacy in science may have a low self-efficacy on history (Zimmerman, 2000).

When applied to education, educators agree that students' belief in their academic capacity plays an important role in their motivation to achieve (Zimmerman, 2000). Students with high self-efficacy accept challenges better and are more willing to undertake tasks compared to students with low self-efficacy (Bandura 
Montebon, D. R. T.

\& Schunk, 1981 as cited by Zimmerman, 2000). When students have high self-efficacy their stress and anxiety levels are lower thus a positive emotion is developed. Moreover, Zimmerman (2000) described that a high self-efficacy belief enables students to regulate their capacity to learn, evaluate their performance, and plan different strategies to deal with matters that may be encountered.

\subsection{Theoretical Framework}

Figure 1 below illustrates the theoretical framework of this research.

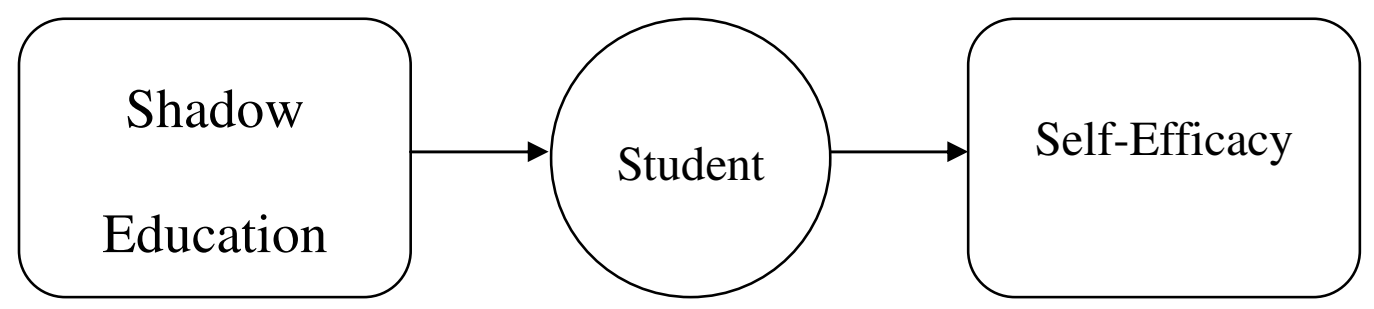

Figure 1. Theoretical Framework on the Effects of Shadow Education on Students' Self Efficacy

Upon the different literature reviewed, the hypothesis that shadow education has a positive effect on the self-efficacy of students has been created. The relationship between two constructs is being considered in this study, shadow education and self-efficacy. Shadow education which in this context refers to the tutorial program that a student attends to is the independent variable of this study. The tutorial sessions attended by students, particularly in science is being hypothesized to have an effect on students' self-efficacy. Self-efficacy in this study refers to the belief of students to achieve in the classroom.

\subsection{Research Problems}

This study aims to investigate the effect of shadow education on students' self-efficacy. Specifically, this research aims to achieve the following objectives.

1. Describe tutorial background of the respondents.

2. Determine the effect of shadow education on students' self-efficacy.

3. Differentiate if there is a significant difference in students' self-efficacy in terms of
a. gender.
b. grade level.
c. the length of attending a tutorial program.

\section{Methodology}

\subsection{Respondents}

This study employed a qualitative survey method research design. The respondents of this research were purposively chosen which are the nineteen $(\mathrm{N}=19)$ tutees of the researcher. Their ages are 14 to 16 years old. All of the respondents are Chinese-Filipino students and their financial status is above average. The demographic details of the respondents are shown in Table 1 below. 
Table 1

Demographics of Respondents $(N=19)$

\begin{tabular}{llcc}
\hline & Group & $\mathrm{n}$ & Percentage Distribution \\
\hline Gender & Male & 9 & $47 \%$ \\
\multirow{3}{*}{ Grade Level } & Female & 10 & $53 \%$ \\
& Grade 8 & 6 & $32 \%$ \\
& Grade 9 & 4 & $21 \%$ \\
& Grade 10 & 9 & $47 \%$ \\
\hline
\end{tabular}

A survey questionnaire was drafted by the researcher to investigate the tutorial background of the respondents and the following questions were asked:

1. How long have you been in a tutorial class?

2. What are the subjects that you tutor?

3. In which area in science do you need help the most?

4. Aside from regular tutorial classes on weekdays, do you go to other special institutions?

5. Why do you tutor?

6. In general, does tutoring help you in class?

7. Will you recommend other students to tutor as well?

The student self-efficacy questionnaire was adapted from Witt-Rose (2013). Modifications on the self-efficacy scale were done prior to implementation. The survey questionnaire on self-efficacy utilized a five-point Likert scale with 1 as strongly disagree and 5 as strongly agree. Upon the reliability tests, the survey instruments had a Cronbach Alpha coefficient of 0.863 .

\section{Results}

\subsection{Tutorial Background of Respondents}

Upon the analysis of the data, it has been found out that $63.2 \%$ of the respondents have been exposed to a tutorial program since they were grade 1 or about 7 to 10 years already. About $21.1 \%$ was found out to be tutoring for about 4-6 years and the rest for about $15.7 \%$ about 1-3 years. The subjects that the respondents tutor the most are math and science $(63.2 \%)$. Specifically, the area in science that the respondents feel that they need help with is Physics (30.6\%), followed by Chemistry (27.8\%), Earth Science (22.2\%), and Biology (19.44\%) respectively. Aside from the regular Math and Science tutorial on weekdays, a number of respondents $(15.8 \%)$ are still going to institutions that offer academic enhancements programs in math and science.

Table 2

Frequency of Students' Reason for Tutoring

\begin{tabular}{lc}
\hline \multicolumn{1}{c}{ Reason } & $f$ of Responses \\
\hline I know I really need help. & $28 \%$ \\
My parents want me to. & $11 \%$ \\
My teachers referred me to. & $0 \%$ \\
Everybody is doing it. & $4 \%$ \\
I want to have good grades. & $30 \%$ \\
I really don't know the reason. & $2 \%$ \\
I have difficulty studying alone at home. & $15 \%$ \\
It will prepare me for college. & $11 \%$ \\
\hline Note. Student responses may be repeated &
\end{tabular}

Based on Table 2, it can be deduced that students acknowledge that they really need help and that they to go 
Montebon, D. R. T.

tutor for them to have good grades. It is also noticeable that in the case of the respondents, the reason to tutor is not because of teachers' referral but of parental and personal reasons. Other students acknowledged their difficulty in studying alone and that they also believe that tutoring can help them when they go to college.

When asked, "Does tutoring help you in class?" all of the respondents (N=19, 100\%) confirmed yes. Also, $100 \%$ of the respondents recommended that other students should.

\subsection{Level of Self-Efficacy of Students}

The extent to which students agree or disagree with the 5-point Likert scale survey items has been interpreted using the following scale: 0.1 to 1.0 as strongly disagree; 1.1 to 2.0 as disagree; 2.1 to 3.0 as neutral; 3.1 to 4 as agree; and 4.1 to 5.0 as strongly agree. Table 3 reports the mean scores obtained for each statement in the self-efficacy scale.

Table 3

Mean of the Responses for the Self-Efficacy Survey $(N=20)$

\begin{tabular}{lcc}
\hline \multicolumn{1}{c}{ Statements } & M & SD \\
\hline I am confident that I have the ability to learn the concepts taught in science. (SE1) & 3.53 & 0.90 \\
I am confident I can do well in science. (SE2) & 3.47 & 1.12 \\
I think I will do as well or better than other students in science. (SE3) & 3.16 & 1.21 \\
I think I will be successful in science. (SE4) & 3.16 & 1.21 \\
I am confident that I can understand the topics taught in science. (SE5) & 3.21 & 1.18 \\
I believe that if I tutor more, I will be successful in science. (SE6) & 3.58 & 0.96 \\
I feel like I know a lot about science compared to other students in our class. (SE7) & 2.68 & 0.89 \\
Compared with other students in our class, I think I have good study skill in science. (SE8) & 2.58 & 0.84 \\
Compared with other students in our class, I feel like I'm a better student. (SE9) & 2.58 & 0.96 \\
I am confident I can do well on the exams in science. (SE10) & 3.11 & 1.15 \\
I am confident I can do well on the practical exams or projects in science. (SE11) & 3.42 & 0.96 \\
I am confident that I can do well in science experiments. (SE12) & 3.47 & 0.96 \\
I think I will receive a passing grade or better in science. (SE13) & 4.11 & 0.94 \\
I am confident that I could explain something learned in class to another person. (SE14) & 3.53 & 0.70 \\
\hline
\end{tabular}

The respondents agreed with ten out of fourteen items in the self-efficacy survey $(M>3.0)$. From the data obtained, the item that gained the only strongly agree response is item number 13 which says "I think I will get a passing grade or better in science" $(M=4.11)$. On the other hand, respondents gave a neutral response for

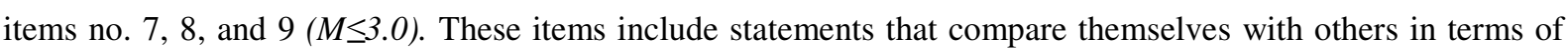
the ability to achieve in science. No disagree and strong responses were recorded.

To interpret the level of efficacy of the respondents, the following scale has been set: 0.1 to 1.0 for very low self-efficacy; 1.1 to 2.0 as low self-efficacy; 2.1 to 3.0 as moderate self-efficacy; 3.1 to 4 high self-efficacy; and 4.1 to 5.0 as very high self-efficacy. Results showed that students under shadow education have a high self-efficacy in general $(M=3.23, S D=0.61)$. There are $16 \%$ of the respondents who have very high self-efficacy $(M \geq 4.1)$. About $37 \%$ of the respondents have high self-efficacy and $47 \%$ have moderate self-efficacy. There are no respondents who have low and very low self-efficacy level.

\subsection{Comparison of Student Self-Efficacy}

The data obtained has been subjected to Shapiro-Wilk test and the results showed that it is normally distributed when grouped per gender and grade level ( $p \geq 0.000$ at sig. 0.05). Therefore, an independent $t$-test was utilized in comparing means for gender while one-way ANOVA was utilized for analysis in grade level. However, when grouped according to the number of years that they are tutoring, the data is not normally distributed. Hence, Kruskal-Wallis test was utilized. Table 4 below reports the analysis for self-efficacy difference based on gender. 
Table 4

T-test for Self-Efficacy on Gender

\begin{tabular}{|c|c|c|c|c|}
\hline Self-Efficacy (SE) & Survey Item & $\mathrm{M}^{\mathrm{a}}-\mathrm{M}^{\mathrm{b}}$ & $\mathrm{t}$ & Sig. (2-tailed) \\
\hline SE1 & & 0.2667 & 0.631 & 0.537 \\
\hline SE2 & & 0.5778 & 1.127 & 0.275 \\
\hline SE3 & & 0.9667 & 1.845 & 0.082 \\
\hline SE4 & & 0.3333 & 0.587 & 0.565 \\
\hline SE5 & & 0.4444 & 0.81 & 0.429 \\
\hline SE6 & & -0.2556 & -0.568 & 0.578 \\
\hline SE7 & & 0.8111 & 2.196 & 0.042 \\
\hline SE8 & & 0.1667 & 0.423 & 0.678 \\
\hline SE9 & & 0.3778 & 0.849 & 0.408 \\
\hline SE10 & & 0.2222 & 0.411 & 0.686 \\
\hline SE11 & & 0.4667 & 1.06 & 0.304 \\
\hline SE12 & & 0.5778 & 1.332 & 0.201 \\
\hline SE13 & & 0.2222 & 0.506 & 0.62 \\
\hline SE14 & & 0.4778 & 1.55 & 0.14 \\
\hline
\end{tabular}

The t-test done on the scores of the respondents on the self-efficacy scale revealed that there is no significant difference on their self-efficacy $(t(17)=0.411$ to $1.845, p=0.14$ to 0.686$)$, except in item SE7 $(t(17)=2.196$, $p=0.42)$. Item SE7 says that "I feel like I know a lot about science compared to other students in our class". In this item the mean score obtained by males $(M=3.11, S D=3.1)$ is higher than the females $(M=2.3, S D=0.82)$.

To test whether there is a significant difference in the self-efficacy of students among different year levels, a one-way ANOVA was conducted. The result of the test showed that students do not have a significant difference in ten out of fourteen items $(F(2,16,18)=0.094$ to 3.37, $p=0.6$ to 0.71). However, a significant difference was observed in items number SE7, SE9, SE11, and SE 12. The results of the ANOVA on the said items are shown in table 5.

Table 5

Mean Comparisons of Students' Self Efficacy among Different Year Levels

\begin{tabular}{lcc}
\hline & \multicolumn{2}{c}{ ANOVA } \\
\cline { 2 - 3 } Self-Efficacy Scale Items & F & Sig. \\
\hline (SE7) I feel like I know a lot about science compared to other students in our class. & 5.678 & 0.014 \\
(SE9) Compared with other students in our class, I feel like I'm a better student. & 3.856 & 0.043 \\
(SE11) I am confident I can do well on the practical exams or projects in science. & 4.409 & 0.03 \\
(SE12) I am confident that I can do well in science experiments. & 5.098 & 0.019 \\
\hline
\end{tabular}
Note. Degrees of freedom are 2, 16, and 18 for ANOVA. The mean difference is significant at the 0.05 level.

The different items that has been found to have a significant difference has been subjected to a Tukey Hoc test to determine the details of the said differences. Upon analysis, it has been found out that among the different grade levels, the average mean score of grade eight 8 is significantly higher than grades 9 and 10 in items SE7, SE9, SE11, and SE12.

The hypothesis that the years of tutoring have a significant difference on the self-efficacy of students undergoing tutorial programs has also been tested using the Kruskal Wallis Test. The result of the said test is shown in Table 6 below. 
Montebon, D. R. T.

Table 6

Difference on the Self-Efficacy of Students as to the Number of Years Tutored

\begin{tabular}{lcccccccccccccc}
\hline & SE1 & SE2 & SE3 & SE4 & SE5 & SE6 & SE7 & SE8 & SE9 & SE10 & SE11 & SE12 & SE13 & SE14 \\
\hline Chi-Square & 3.1 & 2.9 & 2.4 & 3.4 & 2.9 & 2.5 & 2.3 & 1.7 & 3.2 & 2.7 & 2.2 & 5.6 & 2.4 & 4.5 \\
Asymp. Sig. & .375 & .407 & .485 & .339 & .422 & .479 & .505 & .630 & .368 & .446 & .532 & .132 & .502 & .214 \\
\hline Note. $\mathrm{p}=0.05$ & & & & & & & & & & & & & &
\end{tabular}

The result of the Kruskal-Wallis test on Table 6 showed that there is no significant difference in the self-efficacy of the respondents when compared according to the number of years they tutored. The Chi Square statistics $\left(\mathrm{x}^{2}\right)$ ranges from 1.7 to 5.6. All the statistical significance of the test are greater than 0.05 .

\section{Discussion, Conclusions and Implications}

The results of the present research agree with that of the Ireson and Ruthworth (2005) that parents seek the help of tutors to help their children with their academic needs. Perhaps, the students' acknowledgment that they really need help in challenging subjects like math and science, made their parents take them go to tutorial centers. As to the personal experience of the researcher upon his tutorial experience in about eight years already, it has been a constant rationale that kids need help in studying science because their parents could not assist them with it at home. Reasons often times cited would be the lack of time because of attending to their business or the parents themselves find science hard.

The result of the research revealed that students exposed to shadow education have a high self-efficacy in general. Britner and Pajares (2006) determined that one of the factors that promote self-efficacy is social persuasion. In the case of shadow education, the feedback of the tutors matter as may be the case in this research. The continuous moral and academic support provided by the tutor influenced the respondents to have a high self-efficacy. Social persuasion works hand in hand together with other sources of self-efficacy. Another factor to promote self-efficacy described by Britner and Pajares (2005) are physiological states such as anxiety and stress level. Students exposed to shadow education are theorized to have experience lesser academic stress since the support of the tutor in their academic tasks is very much helpful.

It has also been observed in this study that the mean self-efficacy of students do not significantly vary when compared by gender means that shadow education has almost equal impact on students regardless of gender except in one item. In item SE7, males had a higher mean score than females. Such result may have been an offshoot students' inclination towards science. This result disagrees with existing research. According to Williams (2006), females have a higher self-efficacy and motivation in science. However, this research suggests that males have better self-efficacy in science than females. Such result agrees with that of the research of Shumow and Schmidt (2012).

This research also found out that the comparison of student self-efficacy across grade level revealed that grade eight students had a higher self-efficacy in four out of fourteen items. Items SE7 and SE8 allows students to compare themselves with others in terms of achievement in science. The result obtained may have been an effect of the tutor's assistance to the students. Grade eight receive more instructional time than grades nine and ten since the tutor perceive that grade eight students need more help. Schunk and Meece (2005) reported that self-efficacy can be influenced by several factors such as adult and peer support. In this case, an adult support given by the tutor may have been the reason.

In items SE11 and SE12, students were allowed to describe their ability to perform practical exams and experiments in science. Again, grade eight students had a higher self-efficacy than grades nine and ten. This result may have been an influence of the difficulty of science tasks in a classroom. In the study of Shumow and Schmidt (2012), they stated some sources of self-efficacy. One of such is the physical and emotional state of a student. The stress towards a difficult science task may have lowered the self-efficacy of the students in grades 9 
and 10 .

Lastly, the results of this research revealed that the students' self-efficacy does not significantly vary when compared as to the length of time that they spent in tutor classes. The number of years that each child spent tutoring has the same effect on their self-efficacy. One construct that affects self-efficacy is mastery experience. It is doing something over a period of time successfully. Bandura (1994) stressed that mastery concept is the best way to uplift the self-efficacy of a person. In view of the present research, mastery concept is theorized to have influenced the not significant result. Students encounter new learning challenges as they proceed in a certain year level. Thus, their mastery experience is expected to vary at different grade levels.

\subsection{Implications on Practice and Mainstream Education}

This study affirms the role of the shadow education as a support system to mainstream education. Shadow education enables students to have a good self-efficacy towards their studies. Though, the main goal of shadow education is to help students academically, the self-efficacy that was investigated revealed that it also influences the personal aspects of a student. Thus, in this context, shadow education is being recommended. Though it is clear that the role of a shadow teacher is to help students with their studies, this study suggests that shadow education teachers should be more responsible with their students since they affect students in terms of self-efficacy. As this study revealed that students who had more time spent with the tutors had a higher self-efficacy, shadow teachers should bear in mind that students, though of different grade levels, need equal help since their challenges are not equal. This research further implies that parents who entrusts their children to shadow teachers should not fully depend on tutors to do all the responsibility. Parental support is still needed to boost students' self-efficacy. Same goes with the mainstream teacher to just allow the tutors to do all the teaching to the students. It can be observed that in general, students' self-efficacy is 'high'; still it did not reach the 'very-high' mark. Factors such as parental and teacher support could be a factor to increase students' self-efficacy.

\subsection{Recommendation}

This research is subjected to different limitations. First, this study involves only nineteen students who were purposively chosen to be the respondents of this study. Thus, the results of this research could not represent the whole students that are doing after school tutorial in the whole Philippines. Therefore, it is suggested that the study be conducted with a larger respondent coming from different areas of the country. Second, the respondents are of Chinese-Filipino descent. Therefore, this research could not signify other culture. Pure Filipinos that are also having tutorial programs should also be studied to determine their self-efficacy as well. Upon doing so, results could be compared and investigate whether there is a significant difference between tutorial experiences in terms of culture orientation. Lastly, this research focuses on the impact of shadow education in the self-efficacy of students in science only. Impacts of shadow education on the self-efficacy of students towards other subjects were not studied. Therefore, it is recommended that the impact of shadow education on students' self-efficacy in other subjects might also be considered.

\section{References}

Bandura, A. (1977). Self-efficacy: Toward a unifying theory of behavioral change. Psychological Review, 84(2) 191-215. http://dx.doi.org/10.1037/0033-295X.84.2.191

Bray, M., \& Lykins, C. (2012). Shadow education: Private supplementary tutoring and its implications for policy makers in Asia. Philippines: Asian Development Bank.

Bray, M. (1999). The shadow education system: Private tutoring and its implications on planners. Paris: United Nations Education, Scientific, and Cultural Organization.

De Castro, B., \& De Guzman, A. (2013). Proliferation of shadow education institutions (SEI's) in the Philippines: A time series analysis. The Asia-Pacific Education Researcher, 22(3), 341-345. 
Montebon, D. R. T.

http://dx.doi.org/10.1007/s40299-013-0069-x

Heyneman, S. P. (2011) Private tutoring and social cohesion. Peabody Journal of Education, 86(2), 183-188. http://dx.doi.org/10.1080/0161956X.2011.561662

Ireson, J., \& Rusworth, K. (2005). Mapping and evaluating shadow education. Retrieved from http://www.mathsdoctor.tv/ireson\%20report.pdf

Pajares, F., \& Britner, S. (2006). Sources of science self-efficacy beliefs of middle school students. Journal of Research in Science Teaching, 43(5), 485-499. http://dx.doi.org/10.1002/tea.20131

Self-Efficacy Theory. (n.d.) Retrieved from http://samples.jbpub.com/9781449689742/Chapter2.pdf

Witt-Rose, D. (2003). Student self-efficacy in college science: An investigation of gender, age, and academic achievement. Unpublished Master's thesis, The Graduate School University of Wisconsin-Stout.

Zimmerman, B. (2000). Self-efficacy: An essential motive to learn. Contemporary Educational Psychology, 25, 82-91. http://dx.doi.org/10.1006/ceps.1999.1016 